\title{
Effect of precooling on high intensity cycling performance
}

\author{
Damian Marsh, Gordon Sleivert
}

\begin{abstract}
Objective-To examine the effects of precooling skin and core temperature on a 70 second cycling power test performed in a warm and humid environment $\left(29^{\circ} \mathrm{C}, 80 \%\right.$ relative humidity).

Methods-Thirteen male national and international level representative cyclists (mean (SD) age 24.1 (4.1) years; height 181.5 (6.2) cm; weight $75.5(6.4) \mathrm{kg}$; maximal oxygen uptake $\left(\dot{V}_{\text {}_{\text {peak }}}\right) 66.1 \quad(7.0)$ $\mathrm{ml} / \mathrm{kg} / \mathrm{min}$ ) were tested in random order after either 30 minutes of precooling using cold water immersion or under control conditions (no precooling). Tests were separated by a minimum of two days. The protocol consisted of a 10 minute warm up at $60 \%$ of $\dot{\mathbf{V}} \mathrm{O}_{2 \text { peak }}$ followed by three minutes of stretching. This was immediately followed by the 70 second power test which was performed on a standard road bicycle equipped with $172.5 \mathrm{~mm}$ powermeter cranks and mounted on a stationary ergometer.
\end{abstract}

Results-Mean power output for the 70 second performance test after precooling was significantly $(p<0.005)$ increased by $3.3(2.7) \%$ from 581 (57) W to 603 (60) W. Precooling also significantly $(p<0.05)$ decreased core, mean body, and upper and lower body skin temperature; however, by the start of the performance test, lower body skin temperature was no different from control. After precooling, heart rate was also significantly lower than control throughout the warm up $(\mathrm{p}<0.05)$. Ratings of perceived exertion were significantly higher than the control condition at the start of the warm up after precooling, but lower than the control condition by the end of the warm up $(p<0.05)$. No differences in blood lactate concentration were detected between conditions.

Conclusions-Precooling improves short term cycling performance, possibly by initiating skin vasoconstriction which may increase blood availability to the working muscles. Future research is required to determine the physiological basis for the ergogenic effects of precooling on high intensity exercise.

(Br F Sports Med 1999;33:393-397)

Keywords: precooling; thermoregulation; exercise; skin temperature; core temperature; cycling

Dr G Sleivert, Human

Performance Centre, School of Physical Education,

University of Otago, PO Box

56, Dunedin, New Zealand.

Accepted for publication 15 June 1999

Previous research has indicated that lowering body temperature before exercise (precooling) can be beneficial to endurance performance in the heat. ${ }^{1-4}$ No research, however, has been reported on the effects of precooling for shorter more intense events. This is probably because of the minor role thermoregulation plays during these types of event.

Human movement is at best $25 \%$ energy efficient, with most of the balance of energy dissipated as heat. During exercise, surplus heat may be dispersed by redistributing a proportion of the available blood to the periphery for cooling. As exercise continues and the thermoregulatory demands of the body increase, blood supply to the working muscles is balanced by an increased blood supply to the skin for cooling. ${ }^{5}$ Precooling may be of benefit to athletes competing in shorter sprint type events because a reduction in systemic and local temperature (as occurs with precooling) initiates vasoconstriction at the skin, ${ }^{6}$ which may increase central blood volume. An increase in central blood volume may increase blood flow to the working muscles, which may ${ }^{7}$ or may not ${ }^{89}$ be compromised during exercise in the heat. Increased blood delivery to the working muscles may act to increase oxygen delivery and removal of metabolic byproducts. In addition, cold exposure increases the level of circulating catecholamines, ${ }^{10}{ }^{11}$ which may prove beneficial to high intensity exercise performance.

The purpose of this experiment was to measure the effect of upper body precooling on a 70 second cycling power test performed in a warm and humid environment $\left(29^{\circ} \mathrm{C}, 80 \%\right.$ relative humidity). This test was designed to simulate the $1000 \mathrm{~m}$ time trial or "kilo" in track cycling. It was hypothesised that mean power output during the performance test would be improved after precooling.

\section{Methods}

SUBJECTS AND DESIGN

Thirteen male national and international level representative cyclists (mean (SD) age 24.1 (4.1) years; height $181.5(6.2) \mathrm{cm}$; weight 75.5 (6.4) $\mathrm{kg}$; peak $\mathrm{O}_{2}$ uptake $\left(\mathrm{V}_{2} \mathrm{O}_{2 \text { eak }}\right) 66.1$ (7.0) $\mathrm{ml} / \mathrm{kg} / \mathrm{min}$ ) volunteered as subjects for this study after being informed of the possible risks associated with the procedures and signing a letter of informed consent. This study was approved by the Otago Southern Regional Health Authority ethics review board. A repeated measures experimental design was used, with each subject completing two performance tests in a random balanced order after either no precooling (warm) or precooling (cool). Tests were performed at about the same time of the day, a minimum of two and a maxi- 
PHYSIOLOGICAL TESTING

$\dot{\mathrm{V}}_{\text {2peak }}$ was measured for all subjects using an incremental cycling test and open circuit spirometry (2900 Metabolic Cart, Sensormedics Corp, Yorba Linda, California, USA). Before each test, the flowmeter of the metabolic cart was calibrated using a 3 litre calibration syringe, and the $\mathrm{O}_{2}$ and $\mathrm{CO}_{2}$ gas analysers were calibrated using commercial gases of known concentration. Criteria used to confirm that $\dot{V}_{\mathrm{O}_{\text {peak }}}$ was reached included an $\mathrm{R}$ value exceeding 1.15, attainment of age predicted maximal heart rate, and volitional exhaustion. $\dot{\mathrm{V}} \mathrm{O}_{2 \text { peak }}$ was recorded as the highest mean $\dot{\mathrm{V}} \mathrm{O}_{2}$ over one minute.

\section{PERFORMANCE TESTING}

Mean power output over a 70 second performance test was used as a measure of cycling performance. The 70 second time frame was chosen to simulate the $1000 \mathrm{~m}$ time trial performed in track cycling as this was an estimate of completion time for the level of cyclists participating in this study. Subjects were instructed to refrain from vigorous physical activity or use of any substances (caffeine and alcohol were specified) known to alter performance for a 24 hour period before testing. Cyclists were dressed in cycling shorts and shoes throughout the experiment. Environmental chamber temperature was $29^{\circ} \mathrm{C}$ and relative humidity $80 \%$.

Before each performance test, cyclists performed a normal warm up (10 minutes at $60 \%$ of $\left.\dot{\mathrm{V}}_{\text {2peak }}\right)$ or were precooled before the warm up. There was a 10 minute time lag between the precooling procedure and the warm up to allow the subjects to dress and transfer to the environmental chamber. Immediately after the warm up and before the performance test, cyclists stretched for three minutes then were seated on the bicycle and given a 30 second countdown to the start of the test. The subjects completed all warm up and stretches in the same environment as the performance test $\left(29^{\circ} \mathrm{C}\right.$ and $80 \%$ relative humidity). Throughout the performance test, strong encouragement was provided.

Cyclists were tested on a standard road bicycle equipped with $172.5 \mathrm{~mm}$ Schoberer Rad Mebtechnik (SRM) powermeter cranks (professional model; Schoberer Rad Mebtechnik, Julich, Germany) and mounted on a wind/ mechanically braked cyclosimulator (CS-1000 model; Cateye, Osaka, Japan). The SRM system measures force produced during pedalling using four strain gauge strips built into the chain ring of the bicycle. When combined with pedalling cadence, it provides on line measures of power output and has a coefficient of variation of $2.5 \%$. Saddle and stem height of the bicycle were self selected and a fixed gear of 51:15 was used to simulate a track bike.

PRECOOLING

Cold water immersion was used as the method of precooling. Subjects wore swimming trunks and lay in a water bath with an initial water temperature set to $18^{\circ} \mathrm{C}$. To try to maintain the normal temperature of the major muscles involved in cycling, the legs were removed from the water so that only the torso was immersed. After five minutes, crushed ice was introduced to the bath and water temperature was lowered to between 12 and $14^{\circ} \mathrm{C}$. Adequate precooling was considered achieved when either rectal temperature was lowered by $0.3^{\circ} \mathrm{C}$ from the starting temperature or water immersion had lasted 30 minutes. Warm up was commenced 10 minutes after precooling to allow time for each subject to dry off, dress, and transfer to the environmental chamber.

\section{THERMOREGULATORY MONITORING}

Throughout the experiment, core temperature was monitored using a rectal thermistor, inserted to a depth of $11 \mathrm{~cm}$ past the anal sphincter. Conventional flat copper skin thermistors (Grant, Cambridge, UK) were used to monitor skin temperature at four sites. The sites monitored were: bicep, attached at the midline of the anterior aspect of the left arm at a point midway between the acromion process and the olecranon process; chest, a point $1 \mathrm{~cm}$ inferior to the right axilla, along a line running to the anterior fold to the nipple; thigh, the midline of the left anterior thigh midway between the inguinal crease and the proximal border of the patella; calf, the midline of the medial aspect of the lower right leg at the level of maximal calf girth. All thermistors (rectal and skin) were calibrated in a thermostatically controlled water bath against a -5 to $105^{\circ} \mathrm{C}$ criterion thermometer and connected to a recording telethermometer (Grant 1200 Squirrel Logger).

Mean skin temperature was determined by Ramanathan's formula, ${ }^{12}$ and unweighted averages were used to calculate upper (chest and bicep) and lower body (quadriceps and calf) skin temperature. Mean body temperature was determined from rectal and mean skin temperature using Burton's weighted formula. ${ }^{13}$

\section{PHYSIOLOGICAL MONITORING}

Fingerprick blood samples were collected in 20 $\mu \mathrm{l}$ heparinised capillary tubes at rest immediately before the warm up, in the last minute of the 10 minute warm up, and immediately after completion of the 70 second power test. These blood samples were immediately analysed for lactate concentration using an automated lactate analyser (YSI, Yellow Springs, Ohio, USA). Ratings of perceived exertion were measured using the Borg scale ${ }^{14}$ during the warm up at 30 seconds, five minutes, and at 9.5 minutes. Heart rate was measured telemetrically (Sports tester PE 3000, Polar Electro, Kempele, Finland) and recorded every minute throughout the experiment.

\section{STATISTICAL ANALYSIS}

The SPSS statistical package (release 6.1) was used for statistical analysis. Means (SD) were used to express all data. A paired $t$ test was conducted to examine any differences in mean power output between the two conditions. A two way analysis of variance with repeated measures on two factors (treatment (cool or warm) and time) was performed to determine 

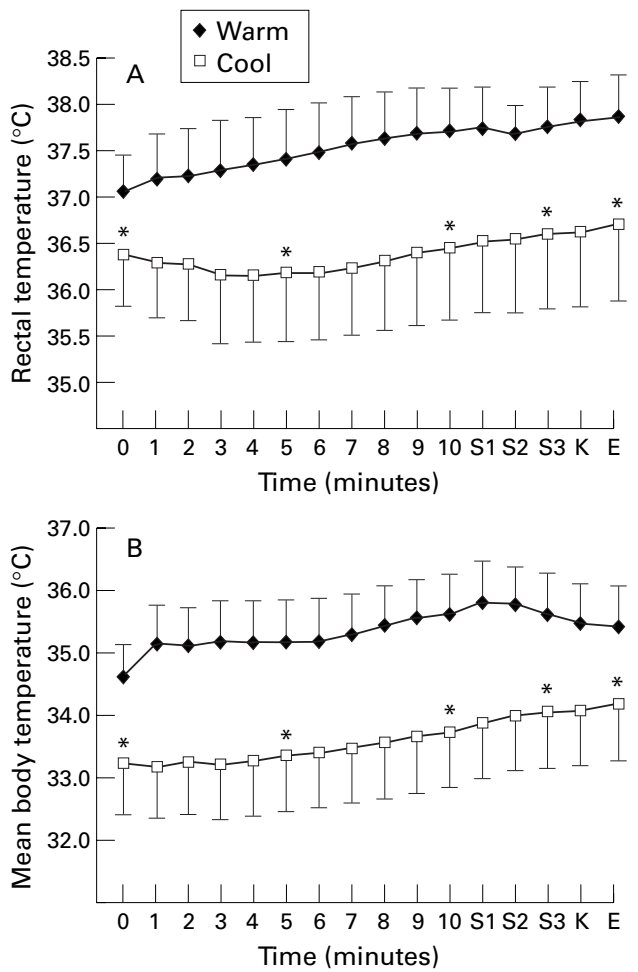

Figure 1 Mean (SD) rectal $(A)$ and mean body (B) temperature throughout the warm up, stretch period, and performance test for warm and cool conditions $(n=13)$. $S 1, S 2$, and S3 indicate minutes 1 to 3 of the stretch period, and $K$ and $E$ indicate the start and end of the 70 second performance test. Statistical comparisons were performed between minutes 0, 5, and 10 of the warm up, the end of the stretch phase, and completion of the time trial. ${ }^{\star}$ Significant difference from the warm condition at the same point in time $(p<0.01)$

if main or interaction effects were present for all thermoregulatory and physiological variables. If significant effects were present, post hoc comparisons were made using paired $t$ tests. Significance was set at $\mathrm{p}<0.05$ except for when multiple post hoc comparisons were made. In these cases the $\mathrm{p}$ value was adjusted using the Bonferroni procedure in order to protect against $\alpha$ inflation.

\section{Results}

Core temperature was significantly lower $(\mathrm{p}<0.05)$ after precooling $\left(36.9(0.4)^{\circ} \mathrm{C}\right)$ than before $\left(37.2(0.4)^{\circ} \mathrm{C}\right)$. Although heart rate and blood lactate concentration respectively appeared slightly higher after precooling (67 (18) bpm and $1.7(0.6) \mathrm{mmol} / \mathrm{l})$ than before (64 (12) $\mathrm{bpm}$ and $1.5(0.5) \mathrm{mmol} / \mathrm{l})$, the differences were not significant. Analysis of variance and post hoc comparisons indicated significantly lower temperatures after precooling at all time points compared for core, mean body, and upper body skin temperatures (figs $1 \mathrm{~A}, \mathrm{~B}$ and $2 \mathrm{~A}$ ). Mean lower body skin temperatures were also significantly lower after precooling during the warm up $(0,5$, and 10 minutes) but no differences were observed after the warm up, during the stretch and performance test (fig $2 \mathrm{~B}$ ).

Heart rate was significantly lower at five and 10 minutes of the warm up after precooling but not different during the power test (fig 3). Conversely, at the start of the warm up, the
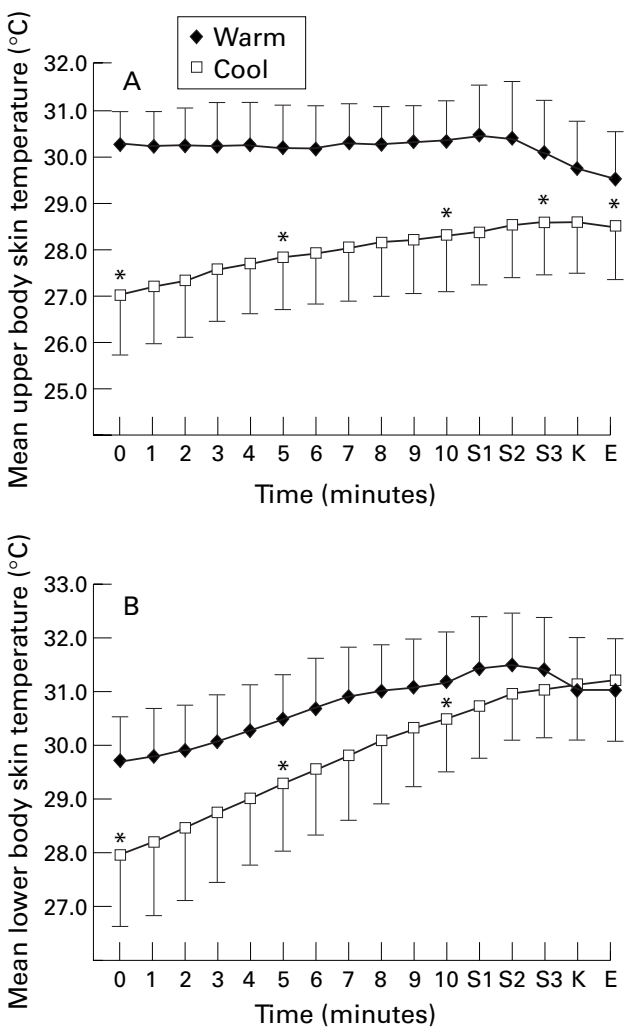

Figure 2 Mean (SD) upper body (A) and lower body (B) skin temperature throughout the warm up, stretch period, and performance test for warm and cool conditions $(n=13) . S 1, S 2$, and $S 3$ indicate minutes 1 to 3 of the stretch period, and $K$ and $E$ indicate the start and end of the 70 second performance test. Statistical comparisons were performed between minutes 0, 5, and 10 of the warm up, the end of the stretch phase, and completion of the time trial. * Significant difference from the warm condition at the same point in time $(p<0.01)$.

rating of perceived exertion was significantly higher after precooling, but by five minutes there were no differences between conditions, and by 10 minutes it was significantly lower for the precooled condition (fig 4). As expected, blood lactate concentration significantly increased over the course of the performance test, but there was no difference between precooling or control conditions (fig 5). Mean

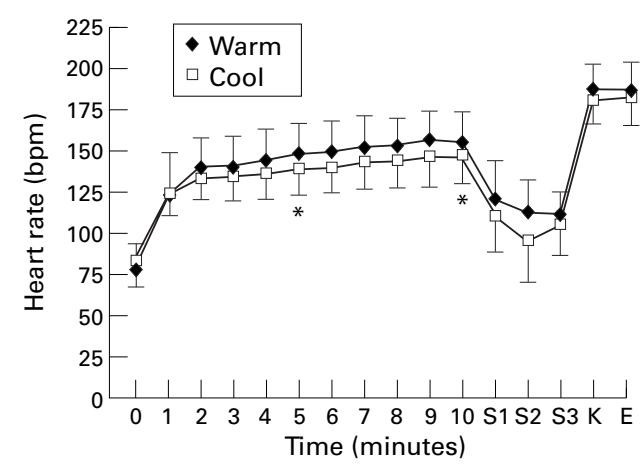

Figure 3 Mean (SD) heart rate throughout the warm up, stretch period, and performance test for warm and cool conditions $(n=13)$. $S 1, S 2$, and $S 3$ indicate minutes 1 to 3 of the stretch period, and $K$ and $E$ indicate the start and end of the 70 second performance test. Statistical comparisons were performed between minutes 0, 5, and 10 of the warm up, the end of the stretch phase, and completion of the time trial. *Significant difference from the warm condition at the same point in time $(p<0.01)$. 


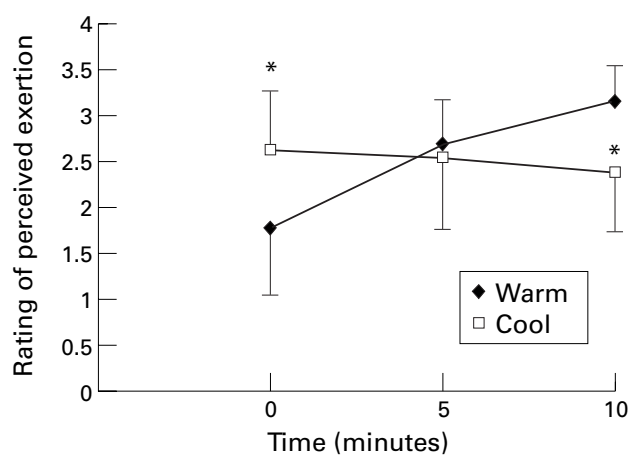

Figure 4 Mean (SD) rating of perceived exertion throughout the warm up for warm and cool conditions ( $n$ =13). *Significant difference from the warm condition at the same point in time $(p<0.01)$.

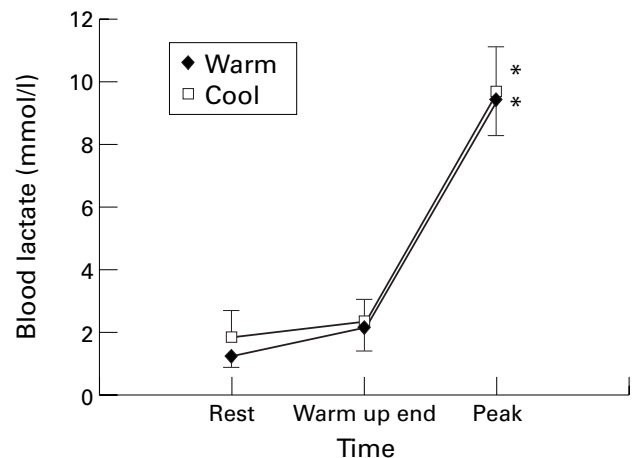

Figure 5 Mean (SD) blood lactate at rest, the end of the 10 minute warm up, and after the completion of the time trial for normal (warm) and precooled (cool) conditions ( $n$ $=13$ ). ${ }^{\star}$ Significant difference from previous time points in the same condition $(p<0.01)$.

70 second power output was significantly $(\mathrm{p}<0.005)$ higher $(3.3(2.7) \%)$ after precooling (603 (66) W) than for the warm condition (581 (57) W)

\section{Discussion}

Previous studies have indicated that precooling can be beneficial to endurance exercise, ${ }^{1-4}{ }^{15}$ but this is the first study to report that precooling can enhance short term high intensity exercise. Precooling lowered core and skin temperature, which in turn probably decreased the need for blood at the skin.

Although no direct blood flow measurements were taken in this study, blood flow is related to local skin temperature, ${ }^{16}$ and there were large decreases in local skin temperatures. It has previously been suggested that during exercise in the heat, decreased peripheral blood flow as a result of precooling may increase central blood volume and enhance blood delivery to the working muscles. ${ }^{2}$ In support of this notion, heart rate during the warm up after precooling was decreased which may suggest increased central blood volume. This decrease in heart rate has also been reported in previous precooling experiments. ${ }^{3}{ }^{17} 18$ Although heart rate was not different during the performance test between conditions, more work was completed in the precooling condition, and this may have masked any possible differences.

An increase in central blood volume may be potentially beneficial to maximal exercise performance. Under conditions of maximal exercise, if a greater central blood volume leads to greater blood availability to the muscle, this would enhance oxygen delivery, resulting in a greater contribution of the aerobic system to energy supply for any given power output. It may also increase the clearance of metabolic byproducts, such as lactate, from the muscle. With greater lactate clearance from the muscle, one may expect higher blood lactate concentrations, but in this experiment no differences in blood lactate concentrations between the two conditions were detected. The reason for this is not clear, but it may be due to several factors. Firstly, increased blood flow to the working muscle may increase the contribution of aerobic metabolism to energy supply and decrease blood lactate accumulation. Secondly, although a higher muscle blood flow may favour an increased rate of lactate removal through increased $\mathrm{pH}$ gradients, the increase in the absolute amount of lactate in the blood may be quite transient, as lactate can be rapidly oxidised $^{19}$ and peak lactate is known to have a high coefficient of variation, ${ }^{20}$ as it is influenced by numerous factors.

It is generally accepted that cooling the muscle results in changes that may impair short term muscular performance. ${ }^{21-23}$ However, recent studies suggest that these impairments in muscle function last less than 20 minutes and disappear with moderate exercise. ${ }^{24}$ With this in mind, care was taken in this experiment not to cool the leg muscles. In addition, performance testing did not take place until 20 minutes after precooling, a period that included a 10 minute warm up. Despite cooling of only the upper body, lower body skin temperature did fall, probably as blood reperfused previously hypoperfused colder superficial and peripheral tissue. ${ }^{2526}$ Lower body skin temperature was significantly cooler after precooling at the beginning of the warm up phase; however, these differences were not significant by the end of the warm up. Although muscle temperature was not measured, it is notable that no differences in lower body skin temperature existed between the two conditions by the time of the performance test. If there was an overall reduction in lower body temperature, it may have been detrimental to performance, considering the $Q_{10}$ effect on muscle enzymes and the effect of temperature on contractile characteristics of muscle. ${ }^{27-29}$

Finally, the ratings of perceived exertion may have also influenced performance. Notably, subjects felt worse at the beginning of the warm up after precooling probably because of cold skin, but felt significantly better by the end of the warm up as the working leg muscles and skin warmed up while the rest of the body stayed cool. Even though the subjects were not informed of any potential benefits of precooling, the lower perceived exertion immediately before the performance test may have exerted a placebo effect, which has been recently reported to be in the range of a $2 \%$ performance enhancement in elite athletes. ${ }^{30}$ 
CONCLUSIONS

The results of this study indicate that precooling provides a small but significant performance enhancement for elite cyclists performing high intensity exercise requiring a mix of aerobic and anaerobic energy supply. Performance improvements may be related to cold induced vasoconstriction of the upper body skin resulting in an increased central blood volume. Whether this would result in an increase in blood flow to working muscle is unknown but an increase in muscle blood flow would probably result in increased muscle oxygen delivery and metabolite removal allowing maintenance of a higher exercise intensity. Further research is required to replicate this finding and elucidate the mechanisms involved.

1 Booth J, Marino F, Ward J. Improved running performance in hot humid conditions following whole body precooling. Med Sci Sports Exerc 1997;29:943-9.

2 Lee DT, Haymes EM. Exercise duration and thermoregulatory responses after whole body precooling. I Appl Physio 1995;79:1971-6.

3 Olschewski H, Bruck K. Thermoregulatory, cardiovascular, and muscular factors relating to exercise after precooling. $\mathcal{F}$ and muscular factors relating to

4 Schmidt V, Bruck K. Effect of a precooling maneuver on body temperature and exercise performance. f Appl Physio 1981;50:772-8

5 Febbraio MA. Metabolic responses to exercise in the heat. In: Sutton JR, Thompson MW, Torode ME, eds. Proceedings of the 10th biennial conference: exercise and thermoregulation. 1995:105-13.

6 Pawelczyk JA. Neural control of skin and muscle blood flow during exercise and thermal stress. In: Gisolfi CV, Lamb DR, Nadel ER, eds. Perspectives in exercise science and sports medicine: exercise heat and thermoregulation. Dubuque, IA Brown \& Benchmark, 1993;6:119-70.

7 Bell AW, Hales JRS, King RB, et al. Influence of heat stress on exercise induced changes in regional blood flow in on ex. F Appl Physiol 1983;55:1916-23.

8 Nielsen B, Savard G, Richter EA, et al. Muscle blood flow and muscle metabolism during exercise and heat stress. $\mathcal{F}$ Appl Physiol 1990;69:1040-6.

9 Savard GK, Nielsen B, Laszcznska J, et al. Muscle blood flow is not reduced in humans during moderate exercise flow is not reduced in humans during mode

10 Bloomstrand E Bergh U, Essen-Gustavsson B, et al. Influence of low muscle temperature on muscle metabolism during intense dynamic exercise. Acta Physiol Scand 1984;120:229-36.
11 Galbo H, Houston ME, Christensen NJ, et al. The effect of water temperature on the hormonal response to prolonged swimming. Acta Physiol Scand 1979;105:326-37.

12 Ramanathan LN. A new weighting system for mean surface temperature of the human body. If Appl Physiol 1964;19: 531-3.

13 Burton AC. The average temperature of the tissues of the body. F Nutr 1935;9:264-80.

14 Borg G. Psychological basis of physical exertion. Med Sci Sports Exerc 1982;14:377-81.

15 Hessemer V, Langusch D, Bruck K, et al. Effect of slightly lowered temperatures on endurance performance in humans. $\mathcal{F}$ Appl Physiol 1984;57:1731-7.

16 Nishiyasu T, Shi X, Gillen CM, et al. Comparison of the forearm and calf blood flow response to thermal stress during dynamic exercise. Med Sci Sports Exerc 1992:24:213-

17 Bergh U, Ekblom B. Physical performance and peak aerobic power at different body temperatures. F Appl Physiol 1979; 46:885-9

18 Jose AD, Stitt F, Collison D. The effects of exercise and changes in body temperature on the intrinsic heart rate in man. Am Heart f 1970;79:488-98.

19 Astrand P-O, Hultman E, Juhlin-Dannfeltet A, et al. Disposal of lactate during and after strenuous exercise in humans. F Appl Physiol 1986;61:338-43.

20 Nummela A, Alberts M, Rijntjes R, et al. Reliability and validity of the maximal anaerobic running test. Int $\mathcal{F}$ Sports Med 1996;17(suppl):S97-102.

21 Asmussen E, Boje O. Body temperature and capacity for work. Acta Physiol Scand 1945;10:1-22.

22 Bergh U, Ekblom B. Influence of muscle temperature on the maximal muscle strength and power output in human skeletal muscles. Acta Physiol Scand 1979;107:33-7.

23 Sargeant AJ. Effect of muscle temperature on leg extension force and short-term muscle power output in humans. Eur 7 Appl Physiol 1987;56:693-8.

24 Ruiz DH, Myrer JW, Durrant E, et al. Cryotherapy and sequential exercise bouts following cryotherapy on concentric and eccentric strength in the quadriceps. Fournal of Athletic Training 1993;28:320-4.

25 Burton AC, Edholm OG. Man in a cold environment. $\mathcal{F} \mathrm{Appl}$ Physiol 1955;59:549-52.

26 Webb P. Afterdrop of body temperature during rewarming: an alternative explanation. 7 Appl Physiol 1986;60:385-90.

27 Bigland-Ritchie B, Thomas CK, Rice CL, et al. Muscle temperature, contractile speed, and motoneuron firing rates during human voluntary contractions. F Appl Physiol 1992;73:2457-61

28 Holewijn M, Heus R. Effects of temperature on electromyogram and muscle function. Eur F Appl Physiol 1992;65:5415 .

29 Rome LC. Influence of temperature on muscle recruitment and muscle function in vivo. American Physiological Society 1990;259:R210-22.

30 Clark VR, Hopkins WG, Hawley JA, et al. The size of the placebo effect of a sports drink in endurance cycling performance. Med Sci Sports Exerc 1998;30(suppl):S61.

Take home message

Precooling core and upper body skin temperature but not the legs provides a small but significant performance enhancement for high intensity cycling exercise in the heat requiring a mixture of aerobic and anaerobic energy supply. The mechanisms responsible for the ergogenic effect of precooling on high intensity exercise remain to be determined. 